\title{
Pneumologia
}

\section{Central sleep apnea in patients with heart failure: whom to screen and how to treat? - A brief review}

\author{
Corina-loana Borcea ${ }^{1,2, *}$, Florin-Dumitru Mihălțan ${ }^{1,2}$, Oana-Claudia Deleanu ${ }^{1,2}$ \\ 'Marius Nasta' Institute of Pneumophtisiology, Pneumology 3 Department, 050159 Bucharest, Romania \\ Abstract \\ English: \\ Central sleep apnoea (CSA) in patients with heart failure (HF) has gained considerable interest in the sleep field within the last \\ decade. Early detection and polysomnography (PSG) patterns recently stated, as well as limited therapeutic approaches remain \\ challenging, that of the positive airway pressure (PAP) therapies show positive effects on cardiovascular mortality in randomised \\ controlled trials (RCTs). The era of personalised medicine promotes further analyses of phenotyping of HF patients for individu- \\ alised treatment consecutively.
}

Keywords

\section{Apneea în somn centrală la pacienții cu insuficiență cardiacă: screening și tratament? O scurtă trecere în revistă}

Rezumat
Romanian:
Sindromul de apnee în somn de tip central la pacienții cu insuficiență cardiacă a devenit un subiect de interes în medicina somnului în ultimii ani. Această asociere rămâne o provocare prin necesitatea unui diagnostic precoce și o abordare terapeutică limitată. Nicio terapie cu presiune pozitivă nu influențează mortalitatea de cauză cardiovasculară, conform studiilor recente randomizat controlate. Mai mult, se promoveaza idea de fenotipare a pacienților cu insuficență cardiacă și apnee în somn centrală și tratamentul individualizat al acestor pacienți.

Cuvinte-cheie

apnee in somn de tip central • insuficienta cardiaca • ventilatie non-invaziva $•$ terapie cu presiune pozitiva $\bullet$ oxigen

\begin{abstract}
Abbreviations
AASM, American Academy of Sleep Medicine; AHI, ApnoeaHypopnoea Index; ASV, Adaptive servo-ventilation; CPAP, Continuous positive airway pressure; CSA, Central sleep apnoea; CSR/B, Cheyne-Stokes respiration/breathing; ICSD-3, International Classification of Sleep Disorders (3rd edition); EF, Ejection fraction; GDMT, Guideline directed medical therapy; HF, Heart failure; HFrEF, Heart failure with reduced EF; HFpEF, Heart failure with preserved EF; HFmrEF, Heart failure with mid-range EF; LVEF, Left ventricular ejection fraction; NYHA, New York Heart Association; OSA, Obstructive sleep apnoea; $\mathrm{PaCO}_{2}$, Partial pressure of carbon dioxide; PAP, Positive airway pressure; PB, Periodic breathing; PSG, Polysomnography; RCTs, Randomised controlled trials; SDB, Sleep-disordered breathing.
\end{abstract}

\section{Introduction}

Heart failure (HF) remains a significant public health problem despite the advances in therapies and prevention (1). Up to $80 \%$ of the patients with chronic HF are associated with sleep-disordered breathing (SDB) (2). SDB is classified as obstructive sleep apnoea (OSA) and central sleep apnoea (CSA), the latter often accompanied by what we used to name Cheyne-Stokes respiration/ breathing $(\mathrm{CSR} / \mathrm{B})$. Both types are characterised by repetitive apnoeas and hypopnoeas during sleep but through different mechanisms and impose a negative impact on cardiovascular function and worsen clinical

*Corresponding author: Corina-loana Borcea

E-mail: corina.borcea@umfcd.ro

2 Open Access. (C) 2021 Borcea et al., published by Sciendo

(c) BY-NC-ND This work is licensed under the Creative Commons Attribution-NonCommercial-NoDerivs 4.0 License. 
outcomes with high healthcare costs (2). OSA is caused by an intermittent obstruction in the upper airways, and CSA is caused by periodic pauses in the central ventilatory drive during sleep (3). Although it is the date that SDB treatment improves cardiovascular and minimises the progression into HF, evidence is inadequate on the long term of current treatment choices (4). Moreover, only a small fraction of HF patients receive adequate screening and efficient treatment, with a shortage of practice guidelines. This article provides an updated overview with a focus on risk factors, diagnosis and simplified therapeutic approaches to better recognise CSA among HF patients.

\section{Definition and classification}

\section{SDB events}

SDB events are classified into apnoea and hypopnoea according to the American Academy of Sleep Medicine (AASM). Apnoea represents a complete cessation of breathing over a period of $\geq 10 \mathrm{~s}$ and is further classified into obstructive or central based on the presence or absence of respiratory effort (4). Hypopnoea represents breathing events due to decreased flow over a period of $\geq 10$ s with desaturation or arousal on an electroencephalogram (4).

\section{Central sleep apnoea}

CSA refers to breathing events due to decreased flow with no effort in thoracoabdominal channels (4), which represent more than half of the events during the sleep study. The severity is judged by Apnoea-Hypopnoea Index (AHI): mild disease is defined as an $\mathrm{AHI}$ of $5-15 / \mathrm{h}$, moderate as $15-30 / \mathrm{h}$ and severe $>30 / h$.

\section{Cheyne-Stokes respiration/breathing}

$\mathrm{CSR} / \mathrm{B}$ refers to the historical description of periodic breathing (PB) with apnoeas in HF/stroke (5).

\section{Periodic breathing}

PB refers to a regularly repeating pattern in which normal or increased ventilation alternates with decreased ventilation or without ventilation. As AASM definition, a cyclical rise and fall in ventilation ( $\geq 3$ central respiratory events separated by a crescendo and decrescendo changes in breathing amplitude with a cycle length of $>40 \mathrm{~s}$ ); in addition, $\geq 5$ central respiratory events per hour of sleep associated with a crescendodecrescendo breathing pattern must be recorded over $2 \mathrm{~h}$ of monitoring (6). If the above criteria are not met, CSB is simply listed as a polysomnography (PSG) finding (7). PB is a PSG pattern (Figure 1), associated with various clinical phenomena (e.g. cardiovascular disorders, high altitude and opioid intake) (8).

\section{CSA with PB/CSR}

CSA with $\mathrm{PB} / \mathrm{CSR}$ represents a clinical disorder rather than simply PSG finding, thus with clinical implications, including aetiology (most commonly congestive HF) and prognostic $(2,6)$.

\section{CSA syndrome}

CSA syndrome covers a heterogeneous group of SDB commonly associated with other medical conditions: CSA with CSB/PB; CSA associated with a medical disorder without

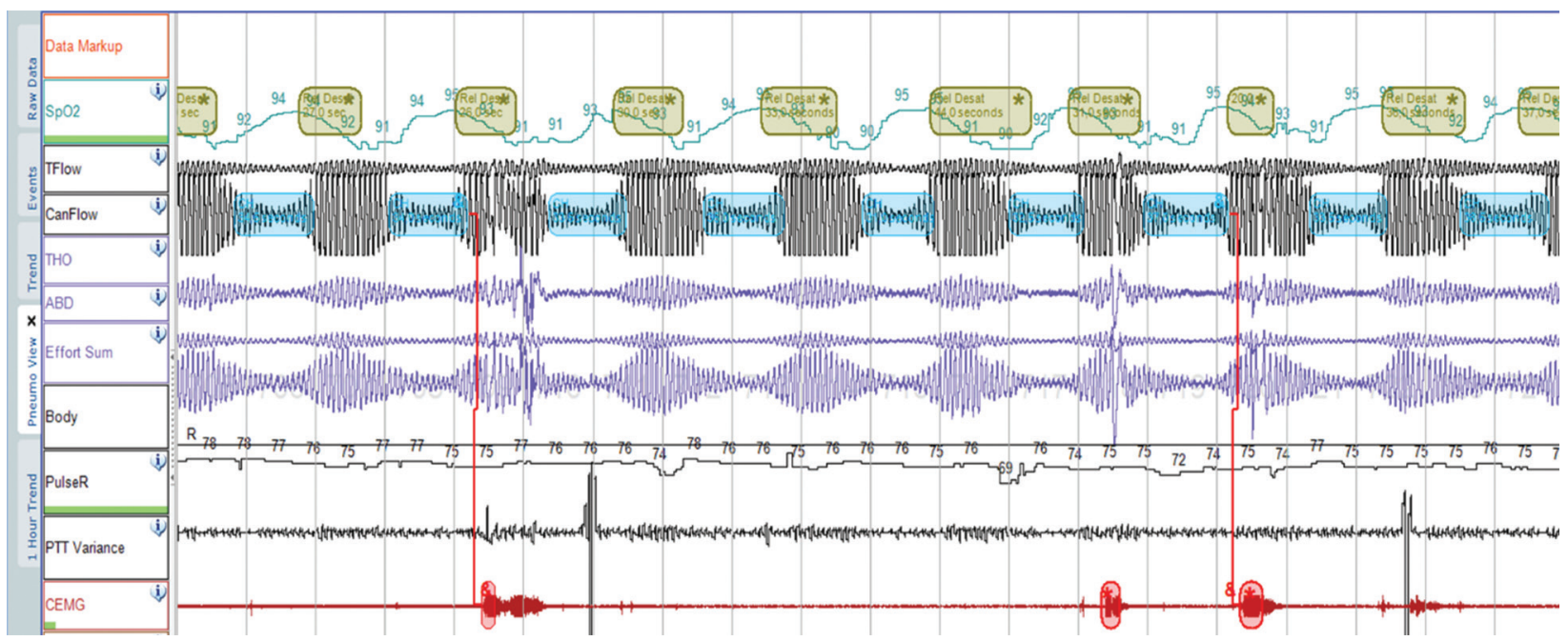

Figure 1. PSG patterns (epoch of $10 \mathrm{~min}$ ) with CSR/PB during N2 stage of sleep in a patient with NYHA II HF, from personal collection. CSR, Cheyne-Stokes respiration; HF, heart failure; NYHA, New York Heart Association; PB, periodic breathing; PSG, polysomnography. 
PB; CSA due to high altitude PB; CSA due to a medication or substance; primary CSA; treatment-emergent CSA (6).

\section{Definition and classification of HF}

\section{Chronic heart failure (CHF)}

$\mathrm{CHF}$ is a clinical syndrome caused by a structural and/or functional cardiac abnormality. Further, HF is phenotyped based on left ventricular ejection fraction (LVEF) in heart failure with reduced $\mathrm{EF}(\mathrm{HFrEF} ;<40 \%)$, heart failure with midrange $\mathrm{EF}$ (HFmrEF; 40-49\%) and heart failure with preserved EF (HFpEF; $\geq 50 \%)(1,9)$.

\section{Mechanisms of CSA in HF}

A review of the literature suggests two basic mechanisms that trigger central respiratory events depending on waking $\mathrm{CO}_{2}$ levels: post-hyperventilation CSA (eucapnic/hypocapnic), which may be triggered by various clinical conditions (cardiac diseases, renal diseases, neuromuscular diseases, obesity hypoventilation syndrome, drugs, high-altitude PB); and CSA secondary to hypoventilation (hypercapnic), which has been described with opioid use $(2,10)$. In CSA, the underlying abnormality is the deregulation of the chemical control of ventilation (11). Patients with HF and CSA are prone to an exaggerated respiratory response to carbon dioxide $\left(\mathrm{CO}_{2}\right)$ and so associated with excess sympathetic nervous activity and grown chemosensitivity (12). A modest rise in partial pressure of carbon dioxide $\left(\mathrm{PaCO}_{2}\right)$ during sleep issues inappropriate hyperventilation, driving $\mathrm{PaCO}_{2}$ below the apneic threshold, at which point the neural drive to respire is too low to stimulate effective inspiration and a respiratory event ensues. $\mathrm{PaCO}_{2}$ subsequently rises and the cycle is repeated. This overshoot of the homeostatic feedback loop is exacerbated by the prolonged circulation time between the alveoli and the brainstem seen in more severe HF. In addition, pulmonary congestion stimulates $\mathrm{J}$ receptors in the lungs, triggering reflex hyperventilation $(12,13)$.

The particular form of PB is not limited to sleep but can occur at rest or during exercise, in patients with advanced $\operatorname{HF}(14,15)$. A recent detailed study demonstrated that $\mathrm{PB}$ is a $24 \mathrm{~h}$ phenomenon that is associated with a worse prognosis in HF (16). Recently, it has been suggested that PB (previously a marker of a poor prognosis) may be a compensatory mechanism in patients with HF (16). Periodic hyperventilation and apnoea may increase end-expiratory lung volume (and therefore oxygen stores), increase vagal tone, aid cardiac pump function, provide intrinsic positive end-expiratory airways pressures and reduce respiratory muscle fatigue (17). PB has been considered as a potential therapeutic target in $\mathrm{HF}$, but diverging experimental findings and contradictory opinions have mounted (18). Large randomised controlled trials (RCTs) (SERVE-HF) analysed the effectiveness of adaptive servoventilation (ASV) on CSA/PB in systolic HF patients and failed to show any prognostic benefits, but rather reported some risk of harm (19).

Although PB is associated with increased mortality in HF patients (19) through oxyhaemoglobin desaturation, arousals, negative intrathoracic pressure, increased sympathetic output, there is no proven beneficial therapy effect on survival $(19,20)$. Focusing on the clinical practice, the PB severity is quantified using the static $\mathrm{AHI}$, or recently, by using hypoxemic burden - time spent at an oxygen saturation $\mathrm{SaO}_{2}$ below $90 \%$ (T90) (21). Relatively large studies looking specifically at the consequences reported as a marker of poor outcome increased chemosensitivity to hypoxia and hypercapnia in HF (21).

\section{Prevalence and prognostic significance}

SDB affects similarly both types of HF (systolic and diastolic) (22). Despite the lower prevalence in the general population compared to OSA (22), CSA (AHI $>15 / \mathrm{h}$ ) is common in HF patients regardless of LVEF (up to $40 \%$ in patients with stable HF) $(23,24)$, but the severity of CSA is related to the severity of HF (8). In addition, CSA worsened during HF exacerbations $(25,26)$ and is reported to be independently associated with a worse prognosis in patients with HFrEF (25). Also dated, CSA is widespread in asymptomatic left ventricular dysfunction and leads to progression to symptomatic HF (2).

Hypertension, coronary artery disease and atrial fibrillation that also contribute to the severity of HF may worsen CSA (27). CSA is not reported to aggravate the above cardiovascular diseases (8).

Under the inadequate evidence on the long-term follow-up, the majority of the studies reported an association between the presence of CSA (AHI $\geq 20$ events/h) and the increased risk of ventricular arrhythmias and death in reduced EF (25, 28). Increased mortality in hospitalised HFrEF patients with CSA was also reported (25).

SchlaHF registry from more than 6500 patients with HFrEF reported a strong association between SDB (either OSA or CSA) and obesity (body mass index $>30 \mathrm{~kg} / \mathrm{m}^{2}$ ). Also, with age over 60, lower resting hypocapnia (wakefulness $\mathrm{PaCO}_{2}<38 \mathrm{mmHg}$ ), atrial fibrillation and poor LVEF were the most important risk factors for CSA/PB vs OSA $(29,30)$. CSA is independently associated with worse outcomes in patients with $\operatorname{HFrEF}(8,25)$ and has a higher socioeconomic burden. 
Other reported risk factors of CSA in patients with HF were male gender, frequent admissions for acute HF, HF severity measured by LVEF (31).

Therefore, the American College of Cardiology/American Heart Association 2017 Focused Update recommends for all patients with New York Heart Association (NYHA) II-IV HF to be screened for sleep apnoea (32). Also are ongoing studies to evaluate pacemakers or defibrillators as a screening tool for SDB (33).

\section{Diagnosis of CSA/PB in HF}

Recognition of CSA is a multileveled and multidisciplinary process that must start with a wide sleep history and concise physical examination and continue with referring high-risk patients for specific sleep testing (9).

\section{Sleep history}

Sleep history should be recorded in all HF patients as a part of the initial evaluation. Symptoms, such as habitual snoring, witnessed apnoeas, nocturnal paroxysmal dyspnoea, daytime sleepiness, fatigue, difficulty in initiating or maintaining sleep, frequent awakenings and impaired memory, must be monitored (7). None of these symptoms has been proven to exclusively predict SDB in HF (32). Because these symptoms are attributed to restrictive sleep and also are commonly reported in HF, SDB is often missed or unrecognised during routine HF evaluation (34).

\section{Patient-based questionnaires}

Patient-based questionnaires for SDB screening (e.g. STOPBANG questionnaire, Epworth sleepiness scale) adds no diagnostic value in the HF population with CSA (30).

\section{Clinical examination in HF}

Shortness of breath (dyspnoea), peripheral oedema and weakness or fatigue are frequent in the HF population (32). These symptoms may occur in the presence of objective signs as jugular vein distension, peripheral oedema and subcrepitant rales. All these characteristics can be caused by a structural and/or functional cardiac abnormality whose consequence will be a lower cardiac outflow with higher intracardiac pressure at rest, but also during extra stress. The term 'HF' is used for the symptomatic phase that can also be graded using the NYHA scale, even though the patient will become asymptomatic with treatment. On the other hand, if a patient is asymptomatic he or she is recommended to be referred to as a patient with asymptomatic left ventricular systolic dysfunction (32). The aetiology of HF should be further investigated because the therapeutic plan can be personalised, as there are cardiovascular and non-cardiovascular causes.

\section{Sleep studies}

Nocturnal PSG with oesophageal pressure measurement in sleep laboratories represents the gold standard and the most comprehensive method for CSA diagnosis; however, this test has many limitations. Thus, ambulatory polygraph (PG) with different surrogates of respiration and/or respiratory effort has a sensitivity and specificity of $90-100 \%$ for the diagnosis of significant CSA in patients with HF compared with PSG $(35,36)$. Stated as studies of type III devices, is monitoring nasal flow, oxygen saturation, thoracic with or without abdominal movement, with acceptable accuracy in differentiating between OSA vs CSA (36). The major limitation of these ambulatory and unattended portable devices is the inability to measure the period of sleep, which could lead to lessening the SDB severity.

In a recent task force, Randerath et al. (8) pointed that observed PSG patterns (central apnoeas, central hypopnoeas, $\mathrm{PB})$ should be identified to improve the current treatment strategies. CSA with $\mathrm{PB} / \mathrm{CSR}$ represents a clinical disorder with symptoms and/or presence of the comorbid conditions are required in ICSD-3 in the absence of other explained sleep disorders. These criteria (A or B) + C + D from the below table could be met both during the diagnosis of PSG or positive airway pressure (PAP) titration (7) (Table 1).

\section{Management of CSA in HF}

There are no current guidelines for the treatment of CSA in patients with HF. Thus the approach for CSA should follow a systematic, multidimensional strategy to ensure appropriate delivery of therapy and guarantee good compliance and longterm efficacy. The optimisation of HF therapy represents a key step in SDB management (32). Moreover, CSA treatment is a long-term commitment because of the chronicity of the disease. Because the effectiveness of treatment highly depends on a high adherence rate, patients should be well informed about their therapeutic choices and participate actively in the decision-making (4).

The recent RCTs show challenging results on current pathophysiology understanding of CSA, and the effects of currently available therapies on clinical outcome are ongoing research (12). Several strategies have been considered for improvement of the ventilation (5).

\section{Optimisation of Medical Therapy}

Guideline directed medical therapy (GDMT) for the HF population should be based on HF stage and functional class. GDMT includes treatment with beta-blockers, which diminished the excessive sympathetic activation (37), angiotensin-converting enzyme inhibitors or angiotensin 
Table 1. Summarises diagnostic criteria for CSA with PB/CSB (adapted from ICSD-3 and Kriger): (A or B) + C + D $(6,7)$.

\begin{tabular}{l}
$\begin{array}{l}\text { A. The presence of sleepiness, difficulty in initiating or maintaining sleep, frequent awakenings or non-restorative sleep, awakening due to shortness of breath, } \\
\text { snoring or witnessed apnoeas }\end{array}$ \\
\hline B. The presence of atrial fibrillation/flutter, stable and decompensated congestive HF or neurological disorder \\
C. PSG (during diagnostic or PAP titration) patterns with all above: \\
1. Five or more central apnoeas and/or hypopnoeas per hour of sleep \\
2. The total number of central apnoeas and/or hypopnoeas over $50 \%$ of the total number of apnoeas and hypopnoeas \\
3. The pattern of ventilation meets the criteria for CSB \\
D. The disorder is not explained more clearly by another current sleep disorder, medication use (e.g. opioids) or substance use disorder \\
CSA, central sleep apnoea; CSB, Cheyne-Stokes breathing; HF, heart failure; PB, periodic breathing; PSG, polysomnography; PAP, positive \\
airway pressure.
\end{tabular}

receptor blockers, which reduce ventricular afterload and enhance cardiac performance (38). Diuretics, ultrafiltration, physical activity, compression stockings or salt restriction can also reduce fluid overload and daytime fluid accumulation in the legs, diminishing nocturnal fluid shift and sleep apnoea (39). Aldosterone antagonists (e.g. spironolactone, eplerenone) improve morbidity and mortality in moderate-to-severe HF (32). Patients should also avoid respiratory depressants such as alcohol, narcotics or anxiolytics. However, these approaches result in a variable and incomplete improvement in $\operatorname{CSA} / \mathrm{PB}(5,32)$.

\section{Nocturnal oxygen $\left(\mathrm{O}_{2}\right)$ supplementation}

Nocturnal oxygen $\left(\mathrm{O}_{2}\right)$ supplementation ameliorates CSA in a patient with HF probably by improving $\mathrm{O}_{2}$ delivery to cardiac muscle and by influencing the loop gain through decreasing hypoxemia and increasing cerebral $\mathrm{CO}_{2} \cdot \mathrm{O}_{2}$ supplementation also decreases nocturnal norepinephrine and BNP levels, improves physical activity and ameliorates quality of life (40). There are contradictory data and in the recent meta-analyses oxygen alone does not improve LVEF or reduces the risk of arrhythmias in HF and CSA/PB (41). $\mathrm{O}_{2}$ supplementation will decrease the $\mathrm{AHI}$ in patients with CSA to a degree comparable to continuous positive airway pressure (CPAP) but will not modify the obstructive events that frequently coexist with central events $(40,42)$.

\section{PAP devices}

\section{Continuous positive airway pressure}

CPAP represents the primary treatment and decreases $\mathrm{AHI}$ by $50 \%$ but does not normalize the respiratory events. CSA was associated with cardiovascular benefit only when the AHI was normalised (43). In the long term ( $>4$ weeks), CPAP decreased the frequency of cardiac premature beats, decreases the severity of mitral regurgitation and increases the LVEF (44). No effects were observed on the arousals index, or quality and efficiency of sleep (44). On short term, PAP therapy leads to better therapy success (45), better blood pressure control
$(44,45)$ and cognitive function (46). However, CPAP did not affect survival (5). In a recent meta-analysis, CPAP is the only therapy to date with randomised statistically significant improvements in LVEF after 3 months (47).

\section{Adaptive servo-ventilation}

ASV was designed for patients with CSA with PB as improving cardiac function, decreases the frequency of all respiratory events and arousals (48). ASV devices try to counterbalance the ventilatory instability during episodes of BP by modulating the degree of inspiratory pressure support (PS), providing positive support during apneic/hypopneic phase and removing this support during the hyperventilatory phase. ASV devices are also capable to provide a fixed or variable expiratory pressure to suppress obstructive events (EPAP) (49). ASV devices are more effective in suppressing $P B$ than conventional PAP devices (47).

Since the results of the SERVE-HF trial published in 2015 reported an increased risk for cardiovascular mortality in the ASV treated patients with chronic HReEF (EF $\leq 45 \%$ ), NYHA II-IV and predominant CSA, ASV is contraindicated in this specific patient population $(8,19)$. However, in clinical practice, most of the patients treated with ASV had severe CSA and treatment-emergent CSA and a history of HFpEF (50).

All current PAP therapies for CSA improve AHI although the duration, effect and the number of patients have varied among therapies (47). Evidence is based on the data that ASV is more efficient in suppressing central apnoeas and hypopnoeas in patients with CSA $(8,51,52)$. Also, ASV improves sleep quality, quality of life, sympathetic activation, NT pro-brain natriuretic peptide and $\operatorname{LVEF}(8,51,53-56)$. ASV normalises the $\mathrm{AHI}$ in patients with $\mathrm{CHF}$ and CSA more effectively compared with CPAP therapy and nocturnal oxygen (evidence A) (8).

These promising data encourage further the purpose of ASV to prevent fatal and non-fatal events in patients with HF and CSA, as RCTs yet have not shown any definite effect on disease prognosis (57) on the comparative effectiveness of CPAP and ASV. A recent meta-analysis concluded that both CPAP and ASV improve the LVEF with cca $5 \%$, which is close 
to the minimum important difference and echocardiographic measurement accuracy in LVEF (58).

Some studies evaluating predictors for ASV usage and reported that patients with impaired sleep structure (short duration of slow-wave sleep), with prospective sleep improvement (59), those with subjective benefit from ASV therapy via proactive patient management (53) and high early ASV usage (between 3 days and 4 weeks) (59) were associated with higher longterm usage of ASV.

\section{Bi-level PAP}

Bi-level PAP decreases both obstructive and central events, increase LVEF and decrease the arousal index. Its efficiency was observed in the cases that associate hypoventilation, especially when it is set-in timed mode. There is some situation when BPAP can aggravate central events by inducing hypocapnia $(60,61)$.

\section{Alternative therapies}

Resynchronising therapy for advanced $\mathrm{HF}$ can decrease $\mathrm{AHI}$ in CSA patients and improve cardiac function, quality of life and mortality (32).

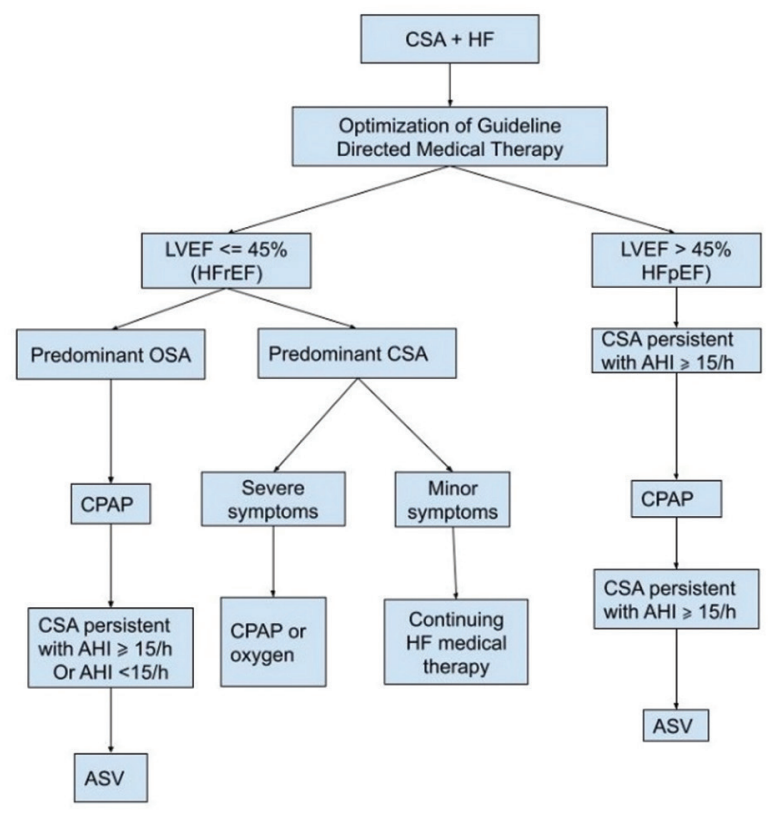

Figure 2. Approach to patients with CSA/PB and HF adapted from published data $(2,9)$. ASV, adaptive servo-ventilation; AHI, ApnoeaHypopnoea Index; CSA, central sleep apnoea; CPAP, continuous positive airway pressure; HF, heart failure; $\mathrm{HFrEF}$, heart failure with reduced EF; HFpEF, heart failure with preserved EF; LVEF, left ventricular ejection fraction; OSA, obstructive sleep apnoea; PB, periodic breathing.
$\mathrm{CO}_{2}$ : Some studies tried to administer supplemental $\mathrm{CO}_{2}$ shifting $\mathrm{pCO}_{2}$ above apneic threshold but $\mathrm{CO}_{2}$ is not recommended in clinical practice $(62,63)$.

Theophylline and acetazolamide, as respiratory stimulants, have been tried but with modest results, with an improvement of $\mathrm{PB}, \mathrm{AHI}, \mathrm{SaO}_{2}$ but with small or no benefit regarding cardiac function or sleep architecture (32).

Phrenic and hypoglossal nerve pacing therapies use a pulse generator to stimulate the diaphragm during sleep. A recent meta-analysis (6 studies, 292 pts in experimental arm) reported the improvement of $\mathrm{AHI}$, quality of sleep (via Epworth score) and quality of life. Moreover, LVEF demonstrated a trend towards improvement in CSA (64).

Regarding cardiac transplantation or left ventricular assist device it is difficult to conclude because of a small number of clinical cases described, but the resolution of CSA is reported (65).

One of the few stepped-care treatments that summarised the of patients with CSA/PB and HF is adapted from published data from Task Force (Figure 2).

\section{Future perspective}

Research in CSA with HF has improved the understanding of the various pathophysiological components, but the evidence is currently still lacking regarding the long-term consequences of CSA and the long-term impact of current strategies in the HF population. Moving forward, the challenge will be to identify the right patient (specific subgroups) who can benefit from these therapies, new strategies (telemedicine, transvenous phrenic nerve stimulation) or new therapeutic target (rostral fluid shift) or to increase compliance. The ongoing RCTs are needed to provide evidence to guide clinical practice.

\section{Conclusions}

With the increasing incidence of $\mathrm{HF}$ and consistent positive correlation with CSA/PB, both cardiology and pulmonology clinicians need to maintain sufficient understanding of this common associated. Clinicians should optimise HF regimens, get screened for SDB with PSG because the patients are often asymptomatic and they have to benefit from diagnosis and treatment. Based on the available data, the use of ASV, CPAP, oxygen, TPNS and medications in CSA with HFrEF demonstrate consistent positive clinical outcomes on sleeprelated metrics, sleep quality, LVEF, and quality of life.

\section{Declaration of interest}

The authors have no conflict of interest to declare. 


\section{References}

1. Benjamin EJ, Blaha MJ, Chiuve SE, Cushman M, Das SR, Deo R, et al. American Heart Association Statistics Committee and Stroke Statistics Subcommittee. Heart Disease and Stroke Statistics-2017 Update: A Report From the American Heart Association. Circulation. 2017;135(10): e146-e603

2. Baillieul S, Revol B, Jullian-Desayes I, Joyeux-Faure M, Tamisier R, Pépin J-L. Diagnosis and management of central sleep apnea syndrome. Expert Review of Respiratory Medicine. 2019;1-13. doi:10.1080/17476348.2019.1604226.

3. Hetland $A$, Vistnes $M$, Haugaa $K H$, Liland $K H$, Olseng $M$, Edvardsen T. Obstructive sleep apnea versus central sleep apnea: prognosis in systolic heart failure. Cardiovascular Diagnosis and Therapy. 2020;10(3): 396-404. doi:10.21037/ cdt.2020.03.02.

4. Kahwash R, Khayat RN. A practical approach to the identification and management of sleep-disordered breathing in heart failure patients. Sleep Medicine Clinics. 2017;12(2): 205-219. doi:10.1016/j.jsmc.2017.01.002.

5. Randerath W, Deleanu O, Schiza S, Pepin J-L. Central sleep apnoea and periodic breathing in heart failure: prognostic significance and treatment options. European Respiratory Review. 2019;28(153): 190084. doi:10.1183/16000617.0084-2019.

6. American Academy of Sleep Medicine. International classification of sleep disorders, 3rd ed. Darien, IL: American Academy of Sleep Medicine; 2014

7. Kryger MH, Roth T, Dement WC. Principles and practice of sleep medicine, 6th ed. Elsevier; 2016. eBook ISBN: 9780323377522, Hardcover ISBN: 9780323242882, Imprint: Elsevier, Published Date: 29th December 2015.

8. Randerath W, Verbraecken J, Andreas S, Arzt M, Bloch KE, Brack T, et al. Definition, discrimination, diagnosis and treatment of central breathing disturbances during sleep. European Respiratory Journal. 2017;49(1): 1600959.

9. Ponikowski P, Voors AA, Anker SD, Bueno H, Cleland JGF, Coats AJS, et al. 2016 ESC guidelines for the diagnosis and treatment of acute and chronic heart failure. European Journal of Heart Failure. 2016;18(8): 891-975. doi:10.1002/ejhf.592.

10. Martins RT, Eckert DJ. Central sleep apnea due to other medical disorders. Sleep Medicine Clinics. 2014;9: 57-67.

11. Pinna GD, Robbi E, Pizza F, Taurino AE, Pronzato C, La Rovere MT, et al. Can cardiorespiratory polygraphy replace portable polysomnography in the assessment of sleep-disordered breathing in heart failure patients? Sleep Breath. 2014;18: 475-482.

12. Eckert DJ, Jordan AS, Merchia P, Malhotra A. Central sleep apnea: pathophysiology and treatment. Chest. 2007;131: 595-607.

13. Spaak J, Egri ZJ, Kubo T, Yu E, Ando S-I, Kaneko Y, et al. Muscle sympathetic nerve activity during wakefulness in heart failure patients with and without sleep apnea. Hypertension. 2005;46:1327-1332.
14. Arzt M, Harth M, Luchner A, Muders F, Holmer SR, Blumberg $F C$, et al. Enhanced ventilatory response to exercise in patients with chronic heart failure and central sleep apnea. Circulation. 2003;107: 1998-2003.

15. Jelic S, Le Jemtel TH. Sleep-disordered breathing in acute decompensated heart failure. Current Heart Failure Reports. 2009;6: 169-175

16. Corra U, Pistono M, Mezzani A, Braghiroli A, Giordano A, Lanfranchi $P$, et al. Sleep and exertional periodic breathing in chronic heart failure: prognostic importance and interdependence. Circulation. 2006;113: 44-50.

17. Naughton MT. Cheyne-Stokes respiration: friend or foe? Thorax. 2012;67: 357-360.

18. Emdin M, Passino C, Giannoni A. After the SERVE-HF trial, is there still a need for treatment of central apnea? Journal of Cardiac Failure. 2015;21: 903-905.

19. Cowie MR, Woehrle H, Wegscheider K, Angermann C, d'Ortho MP, Erdmann E, et al. Adaptive servo-ventilation for central sleep apnea in systolic heart failure. The New England Journal of Medicine. 2015;373(12): 1095-1105.

20. Javaheri S, Shukla R, Zeigler H, Wexler L. Central sleep apnea, right ventricular dysfunction, and low diastolic blood pressure are predictors of mortality in systolic heart failure. Journal of the American College of Cardiology. 2007;49: 2028-2034.

21. Oldenburg $\mathrm{O}$, Wellmann B, Buchholz A, Bitter T, Fox H, Thiem $\mathrm{U}$, et al. Nocturnal hypoxaemia is associated with increased mortality in stable heart failure patients. European Heart Journal. 2016;37: 1695-1703.

22. Heinzer R, Vat S, Marques-Vidal P, Marti-Soler H, Andries D, Tobback $\mathrm{N}$, et al. Prevalence of sleep-disordered breathing in the general population: the HypnoLaus study. The Lancet Respiratory Medicine. 2015;3:310-318.

23. Yumino D, Wang $H$, Floras JS, Newton GE, Mak S, Ruttanaumpawan $\mathrm{P}$, et al. Prevalence and physiological predictors of sleep apnea in patients with heart failure and systolic dysfunction. Journal of Cardiac Failure. 2009;15: 279-285.

24. Sin DD, Fitzgerald F, Parker JD, Newton G, Floras JS, Bradley TD. Risk factors for central and obstructive sleep apnea in 450 men and women with congestive heart failure. American Journal of Respiratory and Critical Care Medicine. 1999;160: 1101-1106.

25. Khayat R, Jarjoura D, Porter K, Sow A, Wannemacher J, Dohar $\mathrm{R}$, et al. Sleep disordered breathing and post-discharge mortality in patients with acute heart failure. European Heart Journal. 2015;36: 1463-1469.

26. Tremel F, Pepin JL, Veale D, Wuyam B, Siché JP, Mallion JM, et al. High prevalence and persistence of sleep apnoea in patients referred for acute left ventricular failure and medically treated over 2 months. European Heart Journal. 1999;20: 1201-1209.

27. Oldenburg O, Bitter T, Fox H, et al. Heart failure. Somnology. 2014;18: 19-25. 
28. Kreuz J, Skowasch D, Horlbeck F, Atzinger C, Schrickel JW, Lorenzen $\mathrm{H}$, et al. Usefulness of sleep-disordered breathing to predict occurrence of appropriate and inappropriate implantable-cardioverter defibrillator therapy in patients with implantable cardioverter-defibrillator for primary prevention of sudden cardiac death. The American Journal of Cardiology. 2013;111: 1319-1323.

29. Arzt M, Woehrle H, Oldenburg O, Graml A, Suling A, Erdmann E, et al. Prevalence and predictors of sleep-disordered breathing in patients with stable chronic heart failure: the SchlaHF Registry. JACC Heart Failure. 2016;4: 116-125.

30. Arzt M, Oldenburg O, Graml A, Erdmann E, Teschler H, Wegscheider $\mathrm{K}$, et al. Phenotyping of sleep-disordered breathing in patients with chronic heart failure with reduced ejection fraction - the SchlaHF registry. Journal of the American Heart Association. 2017;6(12): e005899. doi:10.1161/ JAHA.116.005899.

31. Naughton MT, Kee K. Sleep apnoea in heart failure: to treat or not to treat? Respirology. 2017;22: 217-229.

32. Yancy CW, Jessup M, Bozkurt B, Butler J, Casey DE, Jr., Colvin MM, et al. 2017 ACC/AHA/HFSA focused update of the 2013 ACCF/AHA guideline for the management of heart failure: a report of the American College of Cardiology/American Heart Association Task Force on Clinical Practice Guidelines and the Heart Failure Society of America. Journal of Cardiac Failure. 2017;23(8): 628-651.

33. Gwag HB, Park Y, Lee SS, Kim JS, Park K-M, On YK, et al. Rationale, design, and endpoints of the 'DEvice-Detected CArdiac Tachyarrhythmic Events and Sleep-disordered Breathing (DEDiCATES)' study: prospective multicenter observational study of device-detected tachyarrhythmia and sleep-disordered breathing. International Journal of Cardiology. 2019;280: 69-73.

34. Khayat RN, Jarjoura D, Patt B, Yamokoski T, Abraham WT. In-hospital testing for sleep-disordered breathing in hospitalized patients with decompensated heart failure: report of prevalence and patient characteristics. Journal of Cardiac Failure. 2009;15(9): 739-746.

35. Khayat R, Abraham W, Patt B, Brinkman V, Wannemacher J, Porter K, et al. Central sleep apnea is a predictor of cardiac readmission in hospitalized patients with systolic heart failure. Journal of Cardiac Failure. 2012;18: 534-540.

36. Quintana-Gallego E, Villa-Gil M, Carmona-Bernal C, Botebol-Benhamou G, Martínez-Martínez A, Sánchez-Armengol $A$, et al. Home respiratory polygraphy for diagnosis of sleepdisordered breathing in heart failure. European Respiratory Journal. 2004;24: 443-448.

37. Akira T, Yoshiyuki K, Shigeru N, Munenori K, Kadota J-I. Relationship between -Blocker treatment and the severity of central sleep apnea in chronic heart failure. Chest. 2007;131(1): 130-135.

38. Walsh JT, Andrews R, Starling R, Cowley AJ, Johnston IDA, Kinnear WJ. Effects of captopril and oxygen on sleep apnoea in patients with mild to moderate congestive cardiac failure. British Heart Journal. 1995;73: 237-241.

39. Perger E, Jutant E-M, Redolfi S. Targeting volume overload and overnight rostral fluid shift: a new perspective to treat sleep apnea. Sleep Medicine Reviews. 2018;42: 160-170. doi:10.1016/j. smrv.2018.07.008

40. Shigemitsu M, Nishio K, Kusuyama T, Itoh S, Konno N, Katagiri T. Nocturnal oxygen therapy prevents progress of congestive heart failure with central sleep apnea. International Journal of Cardiology. 2007;115(3): 354-360.

41. Schwarz El, Scherff F, Haile SR, Steier J, Kohler M. Effect of treatment of central sleep apnea/Cheyne-Stokes respiration on left ventricular ejection fraction in heart failure: a network meta-analysis. Journal of Clinical Sleep Medicine. 2019;15(12): 1817-1825. doi:10.5664/jcsm.8092.

42. Nakao YM, Ueshima K, Yasuno S, Sasayama S. Effects of nocturnal oxygen therapy in patients with chronic heart failure and central sleep apnea: CHF-HOT study. Heart Vessels. 2016;31(2): 165-172.

43. Arzt M, Floras JS, Logan AG, Kimoff RJ, Series F, Morrison D, et al. Suppression of central sleep apnea by continuous positive airway pressure and transplant-free survival in heart failure: a post hoc analysis of the Canadian Continuous Positive Airway Pressure for Patients with Central Sleep Apnea and Heart Failure Trial (CANPAP). Circulation. 2007;115(25): 3173-3180.

44. Ryan CM Usui K, Floras JS, et al., Effect of CPAP on ventricular ectopy in heart failure patients with OSA. Thorax 2005;60: 781-785.

45. Antic NA, Catcheside P, Buchan C, Hensley M, Naughton MT, Rowland $\mathrm{S}$, et al. The effect of CPAP in normalizing daytime sleepiness, quality of life, and neurocognitive function in patients with moderate to severe OSA. Sleep. 2011;34(1): 111-119.

46. Wimms A, Ketheeswaran S, Ziegenbein C, Jennings L, Woehrle $\mathrm{H}$. Impact of a new nasal pillows mask on patients' acceptance, compliance, and willingness to remain on CPAP therapy. Sleep Disorder. 2016;2016: 6713236. doi:10.1155/2016/6713236.

47. Voigt J, Emani S, Gupta S, Germany R, Khayat R. Meta-analysis comparing outcomes of therapies for patients with central sleep apnea and heart failure with reduced ejection fraction. The American Journal of Cardiology, 2020;127: 73-83. doi:10.1016/j.amjcard.2020.04.011.

48. Kazimierczak A, Krzyżanowski K, Wierzbowski R, Ryczek R, Smurzyński P, Michałkiewicz D, et al. Resolution of exercise oscillatory ventilation with adaptive servoventilation in patients with chronic heart failure and Cheyne-Stokes respiration: preliminary study. Kardiologia Polska. 2011;69(12): 1266-1271.

49. Javaheri S, Brown LK, Randerath WJ. Positive airway pressure therapy with adaptive servoventilation part 1: operational algorithms. Chest. 2014;146(2): 514-523.

50. Malfertheiner MV, Lerzer C, Kolb L, Heider K, Zeman F, Gfüllner $\mathrm{F}$, et al. Whom are we treating with adaptive servo-ventilation? 
A clinical post hoc analysis. Clinical Research in Cardiology. 2017;106(9): 702-710. doi:10.1007/s00392-017- 11123.

51. Philippe C, Stoica-Herman M, Drouot X, Raffestin B, Escourrou P, Hittinger $L$, et al. Compliance with and effectiveness of adaptive servoventilation versus continuous positive airway pressure in the treatment of Cheyne-Stokes respiration in heart failure over a six month period. Heart. 2006;92(3): 337-342. doi: 10.1136/ hrt.2005.060038.

52. Kasai T, Usui Y, Yoshioka T, Yanagisawa N, Takata Y, Narui K, et al. Effect of flow-triggered adaptive servo-ventilation compared with continuous positive airway pressure in patients with chronic heart failure with coexisting obstructive sleep apnea and Cheyne-Stokes respiration. Circulation: Heart Failure. 2010;3(1): 140-148. doi:10.1161/CIRCHEARTFAILURE.109.868786.

53. Hetzenecker A, Escourrou P, Kuna ST, Series F, Lewis K, Birner $\mathrm{C}$, et al. Treatment of sleep apnea in chronic heart failure patients with auto-servo ventilation improves sleep fragmentation: a randomized controlled trial. Sleep Medicine. 2016;17: 25-31. doi: 10.1016/j.sleep.2015.08.020.

54. Hetzenecker A, Roth T, Birner C, Maier LS, Pfeifer M, Arzt M. Adaptive servo-ventilation therapy of central sleep apnoea and its effect on sleep quality. Clinical Research in Cardiology. 2016;105(3): 189-195. doi: 10.1007/s00392-015-0904-6.

55. D'Elia E, Vanoli E, La Rovere MT, Fanfulla F, Maggioni A, Casali V, et al. Adaptive servo ventilation reduces central sleep apnea in chronic heart failure patients: beneficial effects on autonomic modulation of heart rate. Journal of Cardiovascular Medicine (Hagerstown). 2013;14: 296-300.

56. Oldenburg O, Schmidt A, Lamp B, Bitter T, Muntean BG, Langer $C$, et al. Adaptive servoventilation improves cardiac function in patients with chronic heart failure and Cheyne-Stokes respiration. European Journal of Heart Failure. 2008;10: 581-586.

57. Nakamoto T. Sleep-disordered breathing - a real therapeutic target for hypertension, pulmonary hypertension, ischemic heart disease, and chronic heart failure? Journal of Nippon Medical School. 2018;85(2): 70-77. doi:10.1272/jnms.2018_85-12.

58. Schwarz El, Kohler M. Randomized controlled trials on the comparative effect of treatment modalities of central sleep apnea with Cheyne-Stokes respiration on cardiovascular outcomes and physiology studies required. Journal of Clinical Sleep Medicine. 2020;16(4): 653-654.

59. Kolb L, Arzt M, Stadler S. et al. Adaptive servo-ventilation in patients with chronic heart failure and sleep disordered breathing: predictors of usage. Sleep \& Breathing. 2020. doi:10.1007/ s11325-020-02182-2. [Online ahead of print].

60. McSharry DG, Eckert DJ, Malhotra A. European Respiratory Monograph. 2010;50: 381-395.

61. Noda A, Izawa $H$, Asano $H$, Nakata S, Hirashiki A, Murase $Y$, et al. Beneficial effect of bilevel positive airway pressure on left ventricular function in ambulatory patients with idiopathic dilated cardiomyopathy and central sleep apnea-hypopnea: a preliminary study. Chest. 2007;131(6): 1694-1701.

62. Lorenzi-Filho G, Rankin F, Bies I, Douglas Bradley T. Effects of inhaled carbon dioxide and oxygen on Cheyne-Stokes respiration in patients with heart failure. American Journal of Respiratory and Critical Care Medicine. 1999;159(5 Pt 1): 1490-1498.

63. Xie A, Skatrud JB, Puleo DS, Rahko PS, Dempsey JA. Apnea-hypopnea threshold for $\mathrm{CO}_{2}$ in patients with congestive heart failure. American Journal of Respiratory and Critical Care Medicine. 2002;165(9): 1245-1250.

64. Murtaza G, Turagam MK, Akella K, Madoukh B, Sharma SP, Gopinathannair R, et al. Pacing therapies for sleep apnea and cardiovascular outcomes: a systematic review. Journal of Interventional Cardiac Electrophysiology. 2020. doi:10.1007/s10840020-00760-8. [Online ahead of print].

65. Mansfield DR, Solin P, Roebuck T, Bergin P, Kaye DM, Naughton MT. The effect of successful heart transplant treatment of heart failure on central sleep apnea. Chest. 2003;124: 1675-1681. 